\section{Rib Discoloration: A Physiological Disorder Induced by Heat Stress in Crisphead Lettuce}

\author{
Sylvie Jenni ${ }^{1}$ \\ Agriculture and Agri-Food Canada, Horticultural Research and Development \\ Centre, St-Jean-sur-Richelieu, Quebec, J3B 3E6, Canada
}

Additional index words. Lactuca sativa, rib blight, brown rib, environmental stress, high temperature, development stages

\begin{abstract}
Rib discoloration in crisphead lettuce (Lactuca sativa) has been successfully induced by applying heat stress. Two studies were conducted to determine the effect of short periods ( 3 and 5 days) of high temperatures $\left(35 / 25^{\circ} \mathrm{C}\right.$ and $35 / 15^{\circ} \mathrm{C}$ day/night temperatures) at various developmental stages (at heading, and at 1,2 , and 3 weeks after heading) on rib discoloration incidence and severity. Lettuce (cv. Ithaca) was most sensitive to heat stress 2 weeks after heading: applying $35 / 25^{\circ} \mathrm{C}$ or $35 / 15^{\circ} \mathrm{C}$ day/night temperatures for 3 or 5 days resulted on average in $46 \%$ of mature heads with rib discoloration symptoms. Stressing plants at earlier or later stages resulted in significantly lower incidences of the disorder, with only $4 \%$ to17\% plants showing symptoms. More leaves were affected by the disorder when heat stress was applied 2 weeks after heading than when the stress was applied earlier or later. Night temperature and stress duration had no effect on the incidence and severity of rib discoloration. Up to eight leaves, located between the first and fifteenth leaves acropetal to the cap leaf, showed symptoms. This report establishes a direct relationship between rib discoloration and heat stress, proposes a new method to help lettuce breeders screen germplasm for rib discoloration tolerance, and supports the development of tools for predicting the occurrence of rib discoloration in the field according to meteorological data.
\end{abstract}

Lettuce (Lactuca sativa) is a cool-season crop with optimum temperature for growth in the range of 7 to $24{ }^{\circ} \mathrm{C}$, and an average of 18 ${ }^{\circ} \mathrm{C}$ (Lorenz and Maynard, 1980). Midsummer commercial crisphead lettuce is produced under temperatures often higher than this range, and heads develop physiological disorders such as rib discoloration, bolting and ribbiness, causing major losses in quality and yield (Ryder, 1999).

Rib discoloration symptoms generally appear with warm temperatures and the maturation of lettuce, when the heads are becoming firm enough to meet market requirements. Symptoms begin with a light-brownish discoloration of the midribs of lettuce leaves that form the head (Jenkins, 1959). The discoloration is most intense on the inner surface of outer head leaves and often occurs at the curvature of the prominent midrib (Friedman, 1954; Lipton et al., 1972). Wrapper or cap leaves are rarely

Received for publication 2 May 2005. Accepted for publication 8 July 2005. Agriculture and Agri-Food Canada, Saint-Jean-sur-Richelieu, Que., contribution. This project was supported by a grant from the Matching Investment Initiative (MII) of Agriculture and Agri-Food Canada in collaboration with La Fédération des Producteurs Maraîchers du Québec and Phytodata. Agriculture and Agri-Food Canada, Saint-Jean-sur-Richelieu, Que., Contribution no. 335/2005.09.01R). Thanks to Jean-Claude Desrosiers, Luc Marchand, and Jean-François Dubuc for technical assistance and Natalie Rodrigue for advice on statistical analysis. Use of trade names does not imply endorsement of the products named nor criticism of similar ones not named.

${ }^{1}$ To whom reprint requests should be addressed; e-mail jennis@agr.gc.ca. affected. First light in color, lesions darken to brown or black with time or storage (Marlatt et al., 1957). As the disorder progresses, the discoloration extends to larger and smaller veins and finally to interveinal tissues. The brown streaks along the rib and veins of the leaf are often followed by a soft rot caused by Pseudomonas sp. and other bacteria (Cox, 1955; Friedman, 1954).

The disorder became a problem in commercial lettuce shipments from California, Arizona, Texas, Florida, Georgia, South Carolina, and Virginia when the Great Lakes variety, very susceptible to the disorder, replaced older varieties (Beraha and Kwolek, 1975; Ceponis, 1985; Friedman, 1954). Symptoms were first described around 1945 (Stewart and Foster, 1955) and named rib discoloration in 1954 by Friedman while he was studying a complex of symptoms called brown spot. Microscopic examination and cultures by plant pathologists did not identify fungi or bacteria as causal agents (Cox, 1955; Friedman, 1954).

Because of its physiological and nonpathogenic nature, the disorder received a wide number of names in the early literature. Also reported as rib breakdown (Cox, 1955), brown rib (Jenkins, 1959, 1962; Lipton et al., 1972), red rib (Jenkins, 1959, 1962), and rib blight (Lipton, 1972), the most commonly used name was rib discoloration (Friedman, 1954; Marlatt et al., 1957; Sharples, 1964; Sharples et al., 1963; Stewart and Foster, 1955). In western states, Baggett et al.(1990), Ryder and Robinson (1991), and Ryder et al. (1991) used the term rib discoloration to describe the susceptibility of new varieties of crisphead let- tuce to the disorder. But in Florida, Raleigh and Guzman(1980) described 'Shawnee' lettuce in terms of its resistance to brown rib discoloration or rib blight. Descriptions of the disorders in New York and Chicago markets were made using the term rib discoloration (Beraha and Kwolek, 1975; Ceponis, 1985). That term will be used in this report.

Rib discoloration became prevalent in Florida in hot weather conditions (Cox, 1955). Similarly, the disorder was most severe in the warm, humid weather of North Carolina and occurred when maximum daily temperatures reached 29 to $30{ }^{\circ} \mathrm{C}$ (Jenkins, 1962). In Arizona, lettuce heads harvested in warmer fall or spring months had more incidence of rib discoloration than those harvested in midwinter when nighttime temperatures were near freezing. Sharples et al. (1963) reported a high correlation between the incidence of rib discoloration and average minimum temperature during the 7-d period preceding harvest. Conversely, Jenkins (1959) thought that high incidences of rib discoloration were associated with high daytime temperatures. Indeed, cooling the plants after the heading stage using daily sprinkler irrigation when temperatures were over $27{ }^{\circ} \mathrm{C}$ decreased the severity of rib discoloration symptoms. Variations in the susceptibility to rib discoloration among varieties and breeding lines have been reported (Baggett et al., 1990; Jenkins, 1962; Raleigh and Guzman, 1980; Stewart and Foster, 1955). The addition of nitrogen, calcium or calcium chloride sprays had no effect on the incidence of rib discoloration (Jenkins, 1962).

High incidences of rib discoloration were often observed in the field during the warmest periods of the growing season, but no direct relationship between heat stress and rib discoloration symptoms had been demonstrated in a controlled environment. The developmental stages at which the lettuce plant may be more susceptible to heat stress had not been determined. The objectives of this experiment were to determine 1) if rib discoloration can be induced in a controlled environment by applying heat stress, 2) the critical stage(s) of development at which lettuce is more sensitive to heat stress and will develop rib discoloration symptoms, 3) the effect of nighttime temperature, and 4) the effect of stress duration on the incidence and severity of rib discoloration.

\section{Materials and Methods}

Plants and growth conditions. The growth chamber experiment was conducted at the Agriculture and Agri-Food Canada Horticulture Research and Development Center, Saint-Jean-sur-Richelieu, Quebec, Canada, in 2001 and 2002. 'Ithaca' crisphead lettuce, a variety highly susceptible to rib discoloration (Jenni and Dubuc, 2002), was seeded in growth chambers (Conviron model E-15; Controlled Environments Limited, Winnipeg, Man.) at $18 / 16^{\circ} \mathrm{C}$ day/night temperatures with a $14 \mathrm{~h} / 10$ $\mathrm{h}$ day/night photoperiod. Plants were watered with tap water until the two to three leaf stage, and then with a nutrient solution of $20-8-20$ 
(Plant Product Co., Brampton, Ont.) at a rate of $50 \mathrm{ppm}$ of N. Transplants $25 \mathrm{~d}$ old (four to five leaves) were transplanted in 15 -cm pots (Kord Product, Brampton, Ont.) filled with commercial peat-based medium (Promix BX, Premier Horticulture, Rivière-du-Loup, Que.) on 16 Mar. 2001, and 15 Mar. 2002. Until the high temperature treatments were imposed, the plants were maintained in a greenhouse with a minimum temperature set at $12{ }^{\circ} \mathrm{C}$ and a photoperiod of $14 \mathrm{~h}$ day with supplemental lighting (high-pressure sodium 400-W; Lumiponic, Montreal, Que.) and $10 \mathrm{~h}$ night. During the time when the plants were located in the greenhouse, maximum temperatures averaged $23.3 \pm 0.6{ }^{\circ} \mathrm{C}$, and $24.3 \pm 0.9{ }^{\circ} \mathrm{C}$, and minimum temperatures averaged 12.6 $\pm 0.2{ }^{\circ} \mathrm{C}$, and $14 \pm 0.3{ }^{\circ} \mathrm{C}$ in 2001 and 2002, respectively. Plants were watered three times a week with a nutrient solution of 20-8-20 at a rate of $150 \mathrm{ppm}$ of $\mathrm{N}$, and only with water on the other days. No pesticide was used in the greenhouse or the growth chambers. The plants reached the heading stage (defined as when the plant formed a head of $5 \mathrm{~cm}$ in diameter) on 16 Apr. 2001, and 15 April. 2002. Every week, starting at the heading stage and for a period of 3 weeks, six plants were submitted to heat stress by placing them in each of four growth chambers for a period of 3 or $5 \mathrm{~d}$. Two growth chambers were set at $35 / 15$ ${ }^{\circ} \mathrm{C}$ day/night temperatures, and the other two at $35 / 25{ }^{\circ} \mathrm{C}$ day/night temperatures. All four chambers had a $18 \mathrm{~h} / 6 \mathrm{~h}$ day/night photoperiod. Photosynthetic flux of $400 \mu \mathrm{mol} \cdot \mathrm{m}^{-2} \cdot \mathrm{s}^{-1}$ at the canopy level was obtained from sixteen 1,500-mA fluorescent light tubes (cool white F72T 12/CW/VHO; Osram Sylvania Ltd, Mississauga, Ont.) and twelve $60-\mathrm{W}$ incandescent bulbs (A 19; Osram Sylvania Ltd, Mississauga, Ont.), placed at a height of $0.50 \mathrm{~m}$ to $0.88 \mathrm{~m}$. Plants were returned to the greenhouse after exposure to the high temperature treatments in the growth chambers. Every week from the beginning of the experiment, the plants were randomly rearranged within the replication to minimize potential variations within the growth chambers or the greenhouse.

Experimental design and stress treatments. The effect of three factors, namely four levels of developmental stage, two levels of heat stress, two levels of duration of exposure to heat stress, and their interactions on the incidence and severity of rib discoloration was assessed using a split split-plot design. Lettuce plants reaching each of the four developmental stages (main plot) were submitted to two heat stress treatments (subplots). The two heat stress treatments, 35/15 ${ }^{\circ} \mathrm{C}$ day/night and $35 / 25^{\circ} \mathrm{C}$ day/night, were set to four growth chambers (two replications per heat stress treatment) in which the lettuce plants were placed during two exposure times: three plants were pulled after $3 \mathrm{~d}$, and three others, after $5 \mathrm{~d}$ (sub-sub-plots). In this experimental design, a control group of 12 plants was not submitted to the heat stress and was kept in the greenhouse during the whole experiment. Control samples were informative of potential lack of bias and were omitted from data analyses because of design imbalance.
Data collection and statistical analysis. Plants were evaluated for rib discoloration 25 days after the heading stage on 11 May 2001, and 10 May 2002. Each leaf forming the head was evaluated for rib discoloration and the location of the leaf compared to the flag leaf, i.e., the first leaf forming the head, identified. Incidence was the proportion of plants showing at least one leaf with rib discoloration symptoms, and severity, was the number of leaves with symptoms per plant. Control plants were evaluated at the same time and in the same manner. Data were analyzed using a standard split-split-plot GLM procedure (SAS Institute, 1997) to assess the effects of developmental stage exposure, duration of heat stress and night temperature on rib discoloration incidence and severity. No data transformation was necessary to satisfy homogeneity of variance and normality. Adjusted means were graphically presented with bars representing a confidence interval at the $95 \%$ level.

\section{Results and Discussion}

Rib discoloration symptoms appeared as brown spots and streaks along the main and secondary ribs of the leaves forming the head in plants exposed at 2 weeks after heading, for 3 or $5 \mathrm{~d}$, to $35 / 25{ }^{\circ} \mathrm{C}$ or $35 / 15^{\circ} \mathrm{C}$ day/night temperatures. Symptoms observed on the induced heads looked identical to those naturally induced in the field (Fig. 1). In both years, none of the plants in the untreated controls showed rib discoloration symptoms.

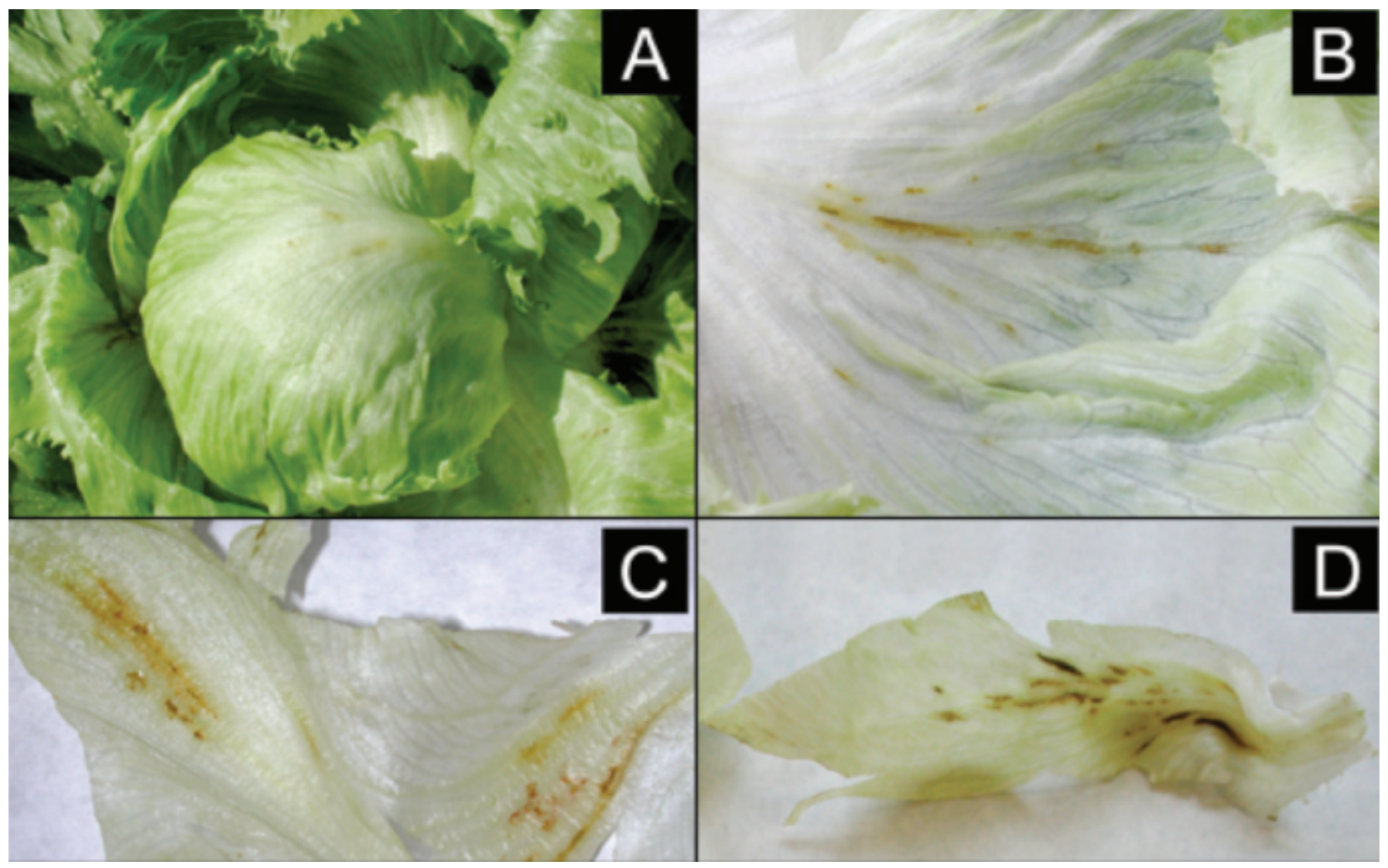

Fig. 1. Rib discoloration on leaf of mature heads of 'Ithaca' lettuce (A and $\mathbf{B})$ from the field, and $(\mathbf{C}$ and $\mathbf{D})$ induced in controlled environment by subjecting plants 2 weeks after the heading stage for $3 \mathrm{~d}$ at $35 / 25^{\circ} \mathrm{C}$ day/night temperatures with a $18 \mathrm{~h} / 6 \mathrm{~h}$ day/night photoperiod. Symptoms are on the exterior (A and $\mathbf{C}$ ) and interior (B and $\mathbf{D})$ side of the leaf. 


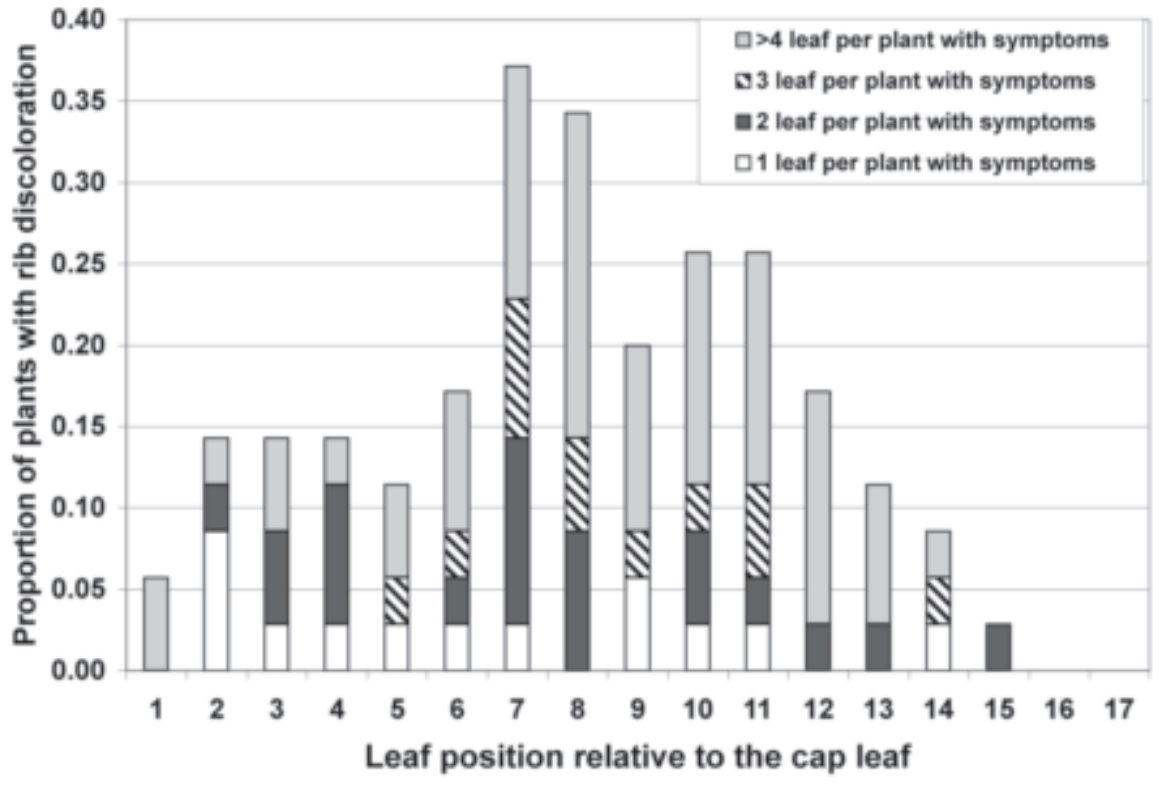

Table 1. Analysis of variance for incidence and severity of rib discoloration symptoms of crisphead lettuce to which a heat stress of $35 / 25^{\circ} \mathrm{C}$ or $35 / 15^{\circ} \mathrm{C}$ day/night temperatures (T) for 3 or $5 \mathrm{~d}(\mathrm{D})$ was applied at four developmental stages $(\mathrm{S})$ in a controlled environment.

\begin{tabular}{|c|c|c|c|}
\hline Source & $\mathrm{df}$ & $\begin{array}{c}\text { Heads with } \\
\text { rib discoloration } \\
(\%)\end{array}$ & $\begin{array}{l}\text { Leaves with } \\
\text { rib discoloration } \\
\text { symptoms } \\
\text { (no.) }\end{array}$ \\
\hline Year (Y) & 1 & NS & NS \\
\hline Developmental stage (S) & 3 & $* * * *$ & $* * * *$ \\
\hline $\mathrm{S} \times \mathrm{Y}$ & 3 & NS & * \\
\hline Night temperature (T) & 1 & NS & NS \\
\hline $\mathrm{T} \times \mathrm{Y}$ & 1 & NS & NS \\
\hline $\mathrm{S} \times \mathrm{T}$ & 3 & NS & NS \\
\hline $\mathrm{S} \times \mathrm{T} \times \mathrm{Y}$ & 3 & NS & NS \\
\hline Duration of heat stress (D) & 1 & NS & NS \\
\hline $\mathrm{D} \times \mathrm{Y}$ & 1 & NS & NS \\
\hline $\mathrm{S} \times \mathrm{D}$ & 3 & NS & NS \\
\hline $\mathrm{T} \times \mathrm{D}$ & 1 & NS & NS \\
\hline $\mathrm{S} \times \mathrm{D} \times \mathrm{Y}$ & 3 & NS & NS \\
\hline $\mathrm{T} \times \mathrm{D} \times \mathrm{Y}$ & 1 & NS & NS \\
\hline $\mathrm{S} \times \mathrm{T} \times \mathrm{D}$ & 3 & NS & NS \\
\hline $\mathrm{S} \times \mathrm{T} \times \mathrm{D} \times \mathrm{Y}$ & 3 & NS & NS \\
\hline
\end{tabular}

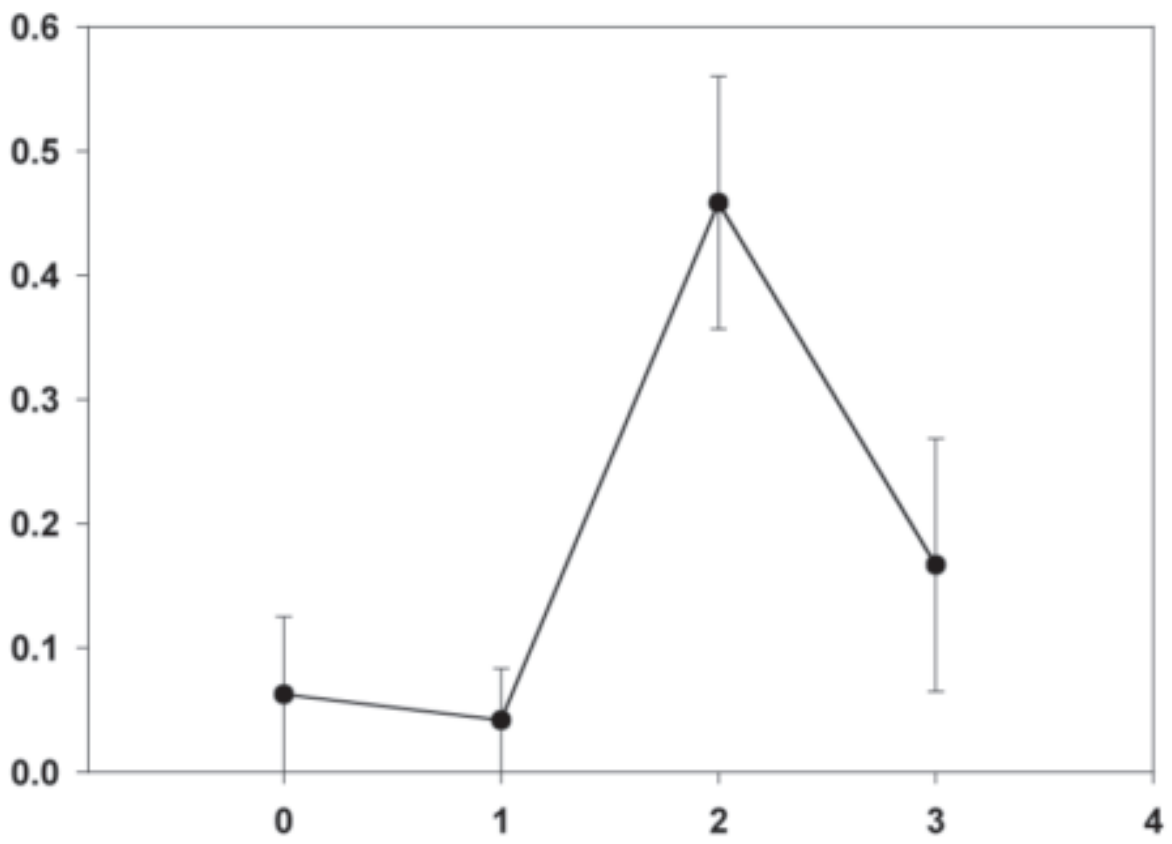

Weeks after the heading stage
Fig. 2. Proportion of crisphead lettuce plants with rib discoloration symptoms according to the position relative to the cap leaf and the number of leaves per head showing symptoms. Data from 35 heads affected by the disorder.

Lesions were located on leaves between the first and fifteenth leaf acropetal to the cap leaf, and most occurred on the seventh and eighth leaf (Fig. 2). This is in contrast with Sharples et al. (1963) who reported that $80 \%$ of the field-grown lettuce heads with rib discoloration symptoms were confined to the fourth and fifth leaf beneath the cap leaf. In this experiment, plants had up to eight leaves with rib discoloration symptoms. When plants had only one leaf with rib discoloration, the symptoms were located between the 2 nd and the fourteenth leaf forming the head (Fig. 2). Similarly, symptoms were scattered between the first and the fifteenth leaf for plants with more severe symptoms, i.e., when lesions were present on two or more leaves.

In the absence of significant two-way, three-way and four-way interactions between developmental stage, night temperature, duration of heat stress, and year, the effect of the developmental stage on the incidence of rib discoloration was consistent among years, intensities and durations of heat stress (Table 1). The developmental stage had a significant effect on the incidence of rib discoloration $(P<0.0001)$, but the night temperature and the duration of the heat stress did not. In both years, applying a heat stress of $35 / 25^{\circ} \mathrm{C}$ or $35 / 15^{\circ} \mathrm{C}$ day/night temperatures for 3 or $5 \mathrm{~d}$, 2 weeks after heading resulted on average in $46 \%$ of mature heads showing rib discoloration symptoms (Fig. 3). In contrast, applying a heat stress at the heading stage, 1 week or 3 weeks after the heading stage resulted in significantly lower incidences of rib discoloration with only $6 \%, 4 \%$, and $17 \%$ plants with rib discoloration symptoms, respectively.

The effect of the developmental stage on rib discoloration severity (number of leaves with rib discoloration symptoms) varied from year to year, as revealed by the significant development stage $\times$ year interaction $(P<0.05$, Table 1). In 2001, applying heat stress 2 weeks after heading induced the rib discoloration of significantly more leaves (1.9 leaves) than when heat stress was applied at the heading stage, 1 week or 3 weeks after heading $(<0.1$ leaf, Fig. 4). In 2002, applying heat stress two weeks after heading resulted in significantly more leaves (1.1 leaf) with rib discoloration than when the stress was applied at heading (0.2 leaf) or at 1 week after the heading stage (0 leaf), but not when the heat stress was applied 3 weeks after heading (0.5 leaf, Fig. 4). This difference in response between the 2 years may have been related to the differences

Fig. 3. Proportion of plants with rib discoloration as a function of the stage of heat stress application. The plants were placed in growth chambers at 35 ${ }^{\circ} \mathrm{C}$ during the day and 15 or $25^{\circ} \mathrm{C}$ during the night for 3 or $5 \mathrm{~d}$, starting each week from the heading stage. Each point is an average of 48 plants. Bars represent $95 \%$ confidence intervals. 

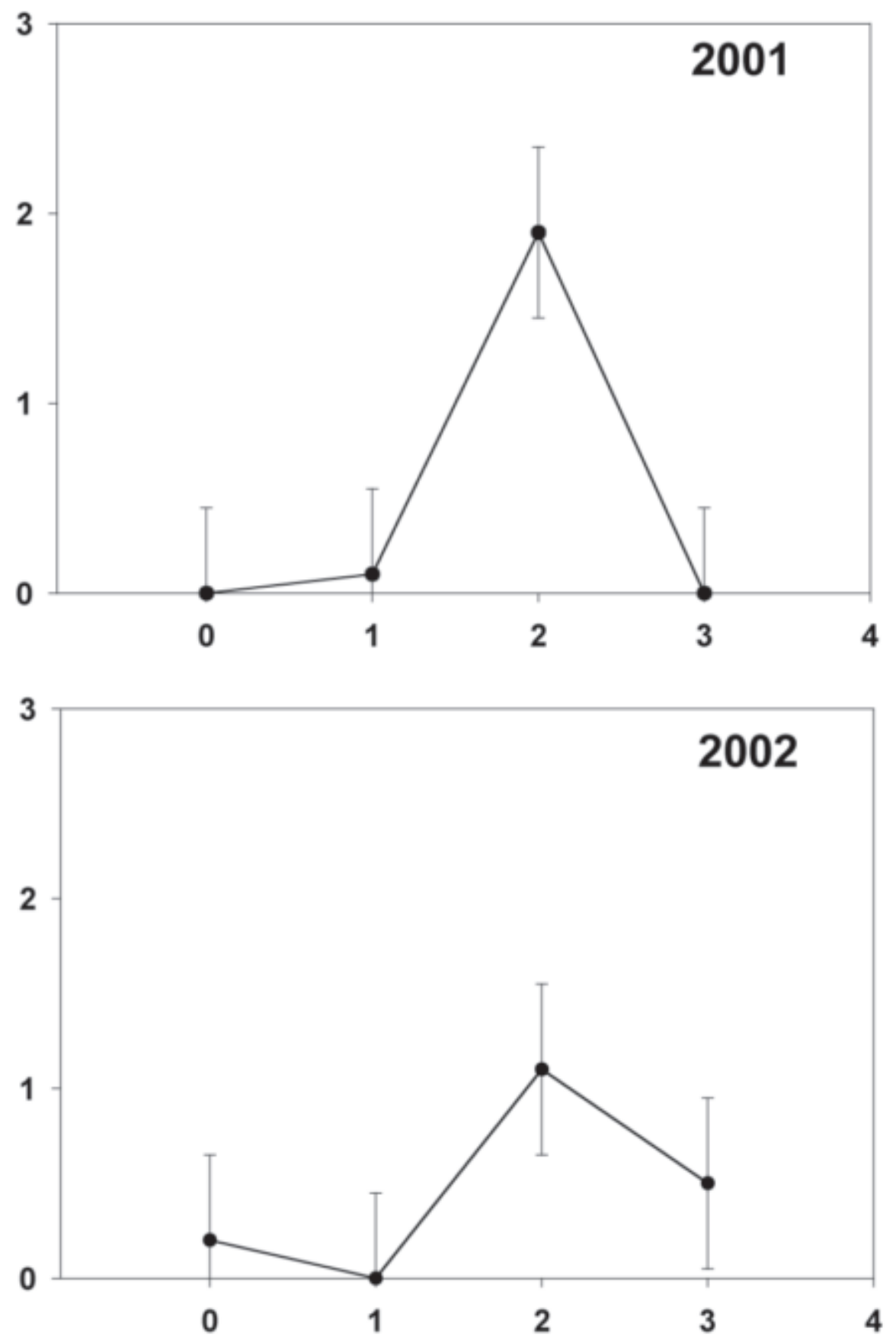

Weeks after the heading stage

Fig. 4. Number of lettuce leaves with rib discoloration as a function of the stage of heat stress application during 2001 and 2002. The plants were placed in growth chambers at $35^{\circ} \mathrm{C}$ during the day and 15 or $25^{\circ} \mathrm{C}$ during the night for 3 to $5 \mathrm{~d}$, starting from the beginning of the heading stage. Each point is an average of 24 plants. Bars represent $95 \%$ confidence intervals.

in temperature experienced in the greenhouse. The warmer growing conditions experienced in the greenhouse in 2002 compared to 2001 may have reenforced the heat stress imposed on plants 3 weeks after heading. Nevertheless, the 2-weeks-after-heading stage was the most sensitive to heat stress and induced the highest incidence of rib discoloration during both years, and the highest severity of symptoms in 2001.

The present work demonstrates a direct relationship between heat stress and rib dis- extended into epidermal and xylem cells as well as lactiferous ducts. Sharples et al. (1963) suggested that browning of lettuce midribs may be of enzymatic origin and reported increases in polyphenol oxidase (PPO) activity in midribs in conditions likely to lead to rib discoloration symptoms. Oxidation of phenolic compounds is involved in tissue browning reactions in many crops (Vamos-Vigyazo, 1981), including lettuce (Fujita et al., 1991; Heimdal et al., 1994; Ke and Salveit, 1989; Tomás-Barberán et al., 1997).

In this experiment, applying cool $\left(15^{\circ} \mathrm{C}\right)$ or high $\left(25^{\circ} \mathrm{C}\right)$ nighttime temperatures did not affect the incidence or severity of rib discoloration when a high $\left(35^{\circ} \mathrm{C}\right)$ daytime temperature was applied (Table 1). It is possible that with a lower daytime temperature, a high nighttime temperature may play a role in the disorder expression, as suggested by Sharples et al. (1963) who associated a high nighttime temperature before harvest with a high incidence of rib discoloration. Overall, the present results agree with Jenkins (1959) who associated high daytime temperature with a high incidence of the disorder. Substantial differences in internal head temperature have been reported in crisphead lettuce during sunny days. In field conditions, the temperature of lettuce heads has exceeded the ambient temperature by 6 to $10{ }^{\circ} \mathrm{C} 3 \mathrm{~h}$ after sunrise (Misaghi and Grogan, 1978). More specifically, the temperature of the $0.6-$ to $1.3-\mathrm{cm}$ portion of the head exceeded the ambient temperature earlier and for longer periods than did the deeper 5.0- to $8.7-\mathrm{cm}$ portion of the head. In this experiment, the temperature below the cap leaves may have well exceeded the 35 ${ }^{\circ} \mathrm{C}$ set in the growth chambers, inducing cell membrane damage and brown lesions in the first 15 leaves forming the head, but not beyond (Fig. 2). The long daily exposure to heat stress (18 h), in this experiment, may explain why the rib discoloration damage was located on leaves deeper in the head when compared with heads of field-grown lettuce.

In field conditions, direct exposure of one side of heads to the sun may create large internal temperature gradients. Lipton (1971) reported that during the warmest part of the day, temperatures at 0.1 and at $4.5 \mathrm{~cm}$ below the cap leaf exposed to the sun exceeded those of ambient air at $10 \mathrm{~cm}$ above soil by 12 and $9{ }^{\circ} \mathrm{C}$, respectively, whereas, on the opposite, cool side of the head, temperatures were $1.5^{\circ} \mathrm{C}$ cooler than ambient air. It would be interesting to verify if rib discoloration damage is likely to appear on the side of the head directly exposed to the sun. Further research is needed to relate the location of rib discoloration damage in the head to the position of the sun.

A better understanding of the effect of the lettuce head structure on leaf and rib temperatures may help in understanding why the developmental stage heading-plus 2 weeks was more sensitive to heat stress and help in designing of lettuce breeding programs that take into account head morphology. The task of lettuce breeders screening for tolerance to rib discoloration and other heat-related physiological disorders is complicated by 
the unpredictability and variability of yearly weather patterns. Other environmental factors such as plant water status, previous growing temperature and air relative humidity also contribute to the intensity of heat stress (Levitt, 1980; Chen et al., 1982). Exposing various genotypes of lettuce for $3 \mathrm{~d}$ at $35 / 15^{\circ} \mathrm{C}$ day/ night temperatures two weeks after heading could be a reliable method for screening for rib discoloration tolerance.

This report is the first showing that rib discoloration can be induced by heat stress applied two weeks after the heading stage. This information supports the development of strategies to predict if a lettuce field is at risk according to meteorological data, and particularly high daytime temperatures. The producer could harvest the field earlier than the expected date, when necessary, since the disorder develops as the lettuce approaches maturity. The 2-weeks-after-heading stage was identified as the critical stage when susceptibility to rib discoloration was highest, and corresponded to $16 \mathrm{~d}$ before harvest. In this experiment, the lettuce plants reached maturity in $61 \mathrm{~d}$, whereas lettuce plants in the Quebec fields mature in 40 to $48 \mathrm{~d}$ when transplanted during the warmest segment of the growing season. Further research is required to validate these results in the field, taking into account fluctuating temperatures and growing cycles, different from the ones used in the present report, under controlled environment.

\section{Literature Cited}

Baggett, J.R., N.S. Mansour, and D. Kean. 1990. Summertime crisphead lettuce. HortScience 25:1453-1454.

Beraha, L. and W.F. Kwolek. 1975. Prevalence and extent of eight market disorders of westerngrown head lettuce during 1973 and 1974 in the Greater Chicago, Illinois, area. Plant Dis. Rpt. 59:1001-1004.

Ceponis M.J. 1985. Disorders in crisphead lettuce shipments to the New York markets, 1972-1984. Plant Dis. 69(11):1016-1020.

Chen, H.H., Z.Y. Shen, and P.H. Li. 1982. Adaptability of crop plants to high temperature stress Crop Sci. 22:719-725.

Cox, R. S. 1955. A preliminary report on diseases of lettuce in the Everglades and their control. Plant. Dis. Rpt. 39:421-423.

Friedman, B. A. 1954. Brown spot complex of head lettuce on eastern markets. Plant. Dis. Rpt. 38(12):847-851.

Fujita, S., T. Tono, and H. Kawahara. 1991. Purification and properties of polyphenol oxidase in head lettuce (Lactuca sativa). J. Sci. Food Agr. 55:643-651.

Heimdal H., L.M. Larsen, and L. Poll. 1994. Characterization of polyphenol oxidase from photosynthetic and vascular tissues (Lactuca sativa). J. Agr. Food Chem. 42:1428-1433.

Jenkins, J.M.J. 1959. Brown rib of lettuce. Proc. Amer. Soc. Hort. Sci. 74:587-590.

Jenkins, J.M.J. 1962. Brown rib resistance in lettuce. Proc. Amer. Soc. Hort. Sci. 81:376-379.

Jenni, S. and J.-F. Dubuc. 2002. Yield and quality of crisphead lettuce cultivated on organic or mineral soils. J. Veg. Crop Prod. 8:3-14.

Ke, D. and M.E. Saltveit. 1989. Wound-induced ethylene production, phenolic metabolism and susceptibility to russet spotting in iceberg lettuce. Physiol. Plant. 76:412-418.

Levitt, J. 1980. Responses of plants to environmental stresses. vol. 1. Chilling, freezing and high temperature stresses. Academic Press, New York.

Lipton, W.J. 1971.Temperature and net energy gain in a growing mature head of lettuce. Agr. Meteorol. 8:429-437.

Lipton, W.J., J.K. Stewart, and T.W. Whitaker. 1972. An illustrated guide to the identification of some market disorders of head lettuce. Agr. Res. Serv., U.S. Dept. Agr., Wash., D.C.

Lorenz, O.A. and D.N. Maynard. 1988. Knott's handbook for vegetable growers. John Wiley and Sons, New York.

Marcum, K.B. 1998. Cell membrane thermostability and whole-plant heat tolerance of kentucky bluegrass. Crop Sci. 38:1214-1218.

Marlatt, R. B., J. K. Stewart, and B. B. Berkenkamp. 1957. Storage of lettuce with rib discoloration. Phytopathology 47:231-233.

Misaghi I.J. and R.G. Grogan. 1978. Effect of temperature on tipburn development in head lettuce. Phytopathology 68:1738-1743.

Paulsen, G.M. 1994. High temperature responses of crop plants, p. 365-389. In: K.J. Boote, J.M. Bennett, T.R. Sinclair, and G.M. Paulsen (eds.). Physiology and determination of crop yield. ASA-CSAA-SSSA, Madison, Wis.

Raleigh, G.L. and V.L. Guzman. 1980. Shawnee a crisphead lettuce adapted to organic soils of Florida. Univ. Fla. Agr. Expt. Sta. Circ. S269:6

Ryder, E.J. 1999. Lettuce, endive and chicory. CAB Intl., New York..

Ryder, E.J. and B.J. Robinson. 1991. Pacific lettuce. HortScience 26:437-438.

Ryder, E.J., W. Waycott, and J.D. McCreight. 1991. Autumn Gold lettuce. HortScience 26:438-439.

SAS Institute, 1997. SAS for Windows, release 6.12. SAS Inst., Cary, N.C.

Sharples, G.C. 1964. Polyphenols content of head lettuce in relation to seasonal temperature. Proc. Amer. Soc. Hort. Sci. 82:391-396.

Sharples, G.C., S. Fazio and P.M. Bessey. 1963. Oxidase activity and discoloration in Great Lakes lettuce in relation to seasonal temperature. Proc. Amer. Soc. Hort. Sci. 84:356-363.

Stewart, J. K. and R. E. Foster. 1955. Observations on rib discoloration and tipburn of lettuce. Plant. Dis. Rpt. 39:418-420.

Tomás-Barberán, F.A., J. Laaiza-Velarde, A. Bonfanti, and M.E. Saltveit. 1997. Early wound- and ethylene-induced changes in phenylpropanoid metabolism in harvested lettuce. J. Amer. Soc. Hort. Sci. 122:399-404.

Vamos-Vigyazo, L. 1981. Polyphenol oxidase and peroxidase in fruits and vegetables. CRC Crit. Rev. Food. Sci. Nutr. 15:49-127. 